\title{
Pseudo-Loadflow Formulation as a Starting Process for the Newton Raphson Algorithm
}

\author{
Malcolm Irving \\ Brunel Institute of Power Systems, Brunel University, UK
}

\begin{abstract}
This paper introduces new models which approximate the AC loadflow problem, but are able to converge (using the Newton Raphson algorithm) from a wider range of starting points. The solution of the pseudo-loadflow models can provide a robust starting process for the Newton Raphson solution of the conventional loadflow problem. It is also shown that pseudo-loadflow solutions exist in many cases where the AC loadflow equations do not appear to have any solution, and in such cases the pseudo-loadflow solution can provide useful information to assist in locating the cause of infeasibility of the AC loadflow model. Test results are presented for illustrative small network examples and also for larger test networks. The computational requirements of the proposed methods are similar to those of the conventional Newton Raphson loadflow algorithm.
\end{abstract}

Index Terms: power flow, Newton Raphson algorithm, starting process.

\section{INTRODUCTION}

The Newton Raphson (NR) algorithm and its variants are probably the most widely used approaches to the solution of the AC loadflow problem [1,2]. Generally, convergence is obtained in a reasonable number of iterations from a 'flat start' initial point. However, in a small number of cases divergence occurs and the analyst 
is faced with a dilemma: either a solution does exist but the numerical method has failed to converge to it from the given starting point, or no solution exists and power network operation is infeasible with the specified loading conditions. Researchers have made significant contributions to this problem, over many years, either by proposing more robust algorithms to converge to a solution more reliably [3-7], or by identifying the conditions under which no physical solution exists [8]. A brief review of many of the significant contributions in this area is included by Milano [7]. Although loadflow solution is now a routine task in power system analysis, the introduction of new system models and new solution methods continues to be of interest [13-17].

The present paper follows an approach originally suggested by Stott [9], by defining a starting process which can provide the conventional Newton Raphson loadflow with an initial set of voltages that are closer to the desired solution than the usual flat start. It is notable that the starting process introduced by Stott directly led to the development of the Fast Decoupled (FD) method [10]. Many practical loadflow algorithms, today, include the option to apply a single iteration of the FD algorithm as a starting process for the NR method. The present paper introduces new models, termed pseudo-loadflows, which are intermediate between the well-known DC loadflow [2] and the full AC loadflow equations. In contrast with the Stott starting process, and the FD method, no decoupling assumptions are introduced, and quadratic convergence is retained by applying the full NR process to the pseudo-loadflow equations. It will be shown that the application of the NR process to the pseudo-loadflow equations allows convergence from a much wider 'basin of attraction' compared to that of the AC model. The pseudo-loadflow solution can then provide a good starting point to obtain convergence of the NR process for the AC loadflow equations, in cases which would diverge otherwise. Pseudo-loadflow solutions also exist in many cases where no AC loadflow solution appears to exist. In such cases the pseudo-loadflow can help the analyst to find the likely causes of infeasibility of the AC loadflow, such as errors in the input data. It is also hoped that the proposed methods may be applicable in cases where the introduction of FACTS devices increases the nonlinearity 
of the loadflow problem [13-15].

\section{PROBLEM FORMULATION}

\subsection{AC loadflow equations}

The AC loadflow equations, in polar form, can be written as:

$$
\begin{aligned}
& P_{i}=V_{i} \sum V_{j}\left(G_{i j} \cos \left(\theta_{i}-\theta_{j}\right)+B_{i j} \sin \left(\theta_{i}-\theta_{j}\right)\right) \\
& Q_{i}=V_{i} \sum V_{j}\left(G_{i j} \sin \left(\theta_{i}-\theta_{j}\right)-B_{i j} \cos \left(\theta_{i}-\theta_{j}\right)\right) \\
& P_{i}=\text { active power injection at busbar } i \text { (per unit) } \\
& Q_{i}=\text { reactive power injection at busbar i (per unit) } \\
& V_{i}=\text { voltage magnitude at busbar } \mathrm{i} \text { (per unit) } \\
& \theta_{\mathrm{i}}=\text { voltage phase angle at busbar i (radians) } \\
& \mathrm{G}_{\mathrm{ij}}=\text { real part of an element of the admittance matrix (per unit) } \\
& \mathrm{B}_{\mathrm{ij}}=\text { imaginary part of an element of the admittance matrix (per unit) } \\
& \text { (The summations indicated are over all nodes.) }
\end{aligned}
$$

The AC loadflow equations are solved iteratively from an initial guess, or starting point, usually with all $\theta_{\mathrm{i}}$ set to zero radians and all $\mathrm{V}_{\mathrm{i}}$ (except at the slack node and voltage controlled nodes) set to 1 per unit. This is called a 'flat start'. The trigonometric functions (sine and cosine) contribute significantly to the nonlinearity of the AC loadflow equations. Indeed, the maximum and minimum values of $\sin \left(\theta_{i}-\theta_{j}\right)$, i.e. +1 and -1 , account for the static stability limit for a two-bus system at $\left|\theta_{\mathrm{i}}-\theta_{\mathrm{j}}\right|=\pi / 2$ radians.

\subsection{Pseudo-loadflow equations (type 1)}

By applying the following truncated Taylor series approximations:

$$
\begin{aligned}
\sin \left(\theta_{\mathrm{i}}-\theta_{\mathrm{j}}\right) & \simeq \theta_{\mathrm{i}}-\theta_{\mathrm{j}} \\
\cos \left(\theta_{\mathrm{i}}-\theta_{\mathrm{j}}\right) & \simeq 1-\left(\theta_{\mathrm{i}}-\theta_{\mathrm{j}}\right)^{2} / 2
\end{aligned}
$$


we obtain a set of pseudo-loadflow equations, which have a solution which approximates the AC loadflow solution for small values of $\left|\theta_{i}-\theta_{j}\right|$.

$$
\begin{aligned}
& P_{i}=V_{i}^{\prime} \sum V_{j}^{\prime}\left(G_{i j}\left(1-\left(\theta_{i}^{\prime}-\theta_{j}^{\prime}\right)^{2} / 2\right)+B_{i j}\left(\theta_{i}^{\prime}-\theta_{j}^{\prime}\right)\right) \\
& Q_{i}=V_{i}^{\prime} \sum V_{j}^{\prime}\left(G_{i j}\left(\theta_{i}^{\prime}-\theta_{j}^{\prime}\right)-B_{i j}\left(1-\left(\theta_{i}^{\prime}-\theta_{j}^{\prime}\right)^{2} / 2\right)\right)
\end{aligned}
$$

These equations, which will be referred to as pseudo-loadflow type-1 (PL-1), are more linear than the original AC equations, but should have solutions $\mathrm{V}_{\mathrm{i}}^{\prime}, \theta_{\mathrm{i}}^{\prime}$ which are quite close to the true AC loadflow solutions $\mathrm{V}_{\mathrm{i}}, \theta_{\mathrm{i}}$, up to reasonable values of $\left|\theta_{i}-\theta_{j}\right|$.

\subsection{Pseudo-loadflow equations (type 2)}

To obtain a further set of pseudo-loadflow equations, which are even less nonlinear, we can introduce the relatively coarse approximation for the cosine terms:

$$
\cos \left(\theta_{\mathrm{i}}-\theta_{\mathrm{j}}\right) \simeq 1
$$

This gives pseudo-loadflow type-2 equations (PL-2):

$$
\begin{aligned}
& P_{i}=V^{\prime \prime} \sum V_{j}^{\prime \prime}\left(G_{i j}+B_{i j}\left(\theta_{i}^{\prime \prime}-\theta_{j}^{\prime \prime}\right)\right) \\
& Q_{i}=V^{\prime \prime}{ }_{i} \sum V_{j}^{\prime \prime}\left(G_{i j}\left(\theta_{i}^{\prime \prime}-\theta_{j}^{\prime \prime}\right)-B_{i j}\right)
\end{aligned}
$$

Although these PL-2 equations only approximate the AC loadflow for quite small $\left|\theta_{\mathrm{i}}-\theta_{\mathrm{j}}\right|$, they have the advantage of having only mild nonlinearity.

Applying the full Newton Raphson process to either the PL-1 or PL-2 equations results in Jacobian matrices with sparsity structures identical to those of the usual AC loadflow Jacobian, and allows quadratic convergence to be obtained. An existing polar-form NR loadflow program can easily be adapted by modifying the mismatch equations and the Jacobian terms. The definition of the relevant Jacobian matrix elements is given in Appendix 1. It should be noted that applying the full Newton Raphson process to PL-1 or PL-2 results in Jacobian equations 
which are different to those obtained by applying the sine and cosine approximations within the conventional AC loadflow Jacobian equation (a technique which has sometimes been used to reduce computer time). Examination of equation (5) shows the relationship of these models to the DC loadflow, which would be obtained from equation (5) by making the further approximations $V^{\prime \prime}{ }_{i} \simeq 1, V^{\prime \prime}{ }_{j} \simeq 1$ and $B_{i j}>G_{i j}$.

\section{TEST RESULTS}

A polar-form NR loadflow program, with sparse matrix solution, has been modified to include options of solving the normal AC, PL-1 or PL-2 models defined in the previous section. A series of computational tests have been performed to investigate the properties of these models.

\subsection{Wide-angle starting points}

A small 3-node network, for which the AC model can easily be solved from a flat start by the Newton Raphson algorithm, is defined in Appendix 2. The convergence of the various models from artificially difficult starting points (based on wide-ranging starting angles, but with initial voltage magnitudes at $1 \mathrm{pu}$ ) is compared in Table 1, which shows the number of iterations required for convergence to a mismatch tolerance of $10^{-8} \mathrm{pu}$. All three models (AC, PL-1 and PL-2) converge successfully within 4 iterations from a flat start. As the starting point is artificially widened, to explore the range of convergence, it can be seen that the PL-1 and PL-2 models can converge when the NR process diverges for the AC model. It is also interesting to note that in some cases (indicated by $*$ in the Table) the AC model and PL-1 models converge to a low voltage solution, whereas PL-2 consistently finds a normal high-voltage solution.

The true AC solution $(\mathrm{V}, \theta)$, the PL-1 solution $\left(\mathrm{V}^{\prime}, \theta^{\prime}\right)$ and PL-2 solution $\left(\mathrm{V}^{\prime \prime}, \theta^{\prime \prime}\right)$ for this test problem are 
presented in Table 2a. The angle differences $\left|\theta_{i}-\theta_{j}\right|$ in the AC solution are relatively small in this example, and the PL-1 and PL-2 solutions are reasonable approximations to the true solution. The low voltage solutions, which were obtained in some cases, are shown in Table $2 b$.

\begin{tabular}{|c|c|c|c|c|c|}
\hline \multicolumn{3}{|c|}{ Starting point (radians) } & \multicolumn{3}{c|}{ Number of iterations required to converge } \\
\hline$\theta_{1}$ & $\theta_{2}$ & $\theta_{3}$ & AC & PL-1 & PL-2 \\
\hline 0.0 & 0.0 & 0.0 & 4 & 4 & 4 \\
\hline 0.0 & -0.5 & -1.0 & 8 & 8 & 4 \\
\hline 0.0 & -1.0 & -2.0 & $9^{*}$ & $9^{*}$ & 4 \\
\hline 0.0 & -1.5 & -3.0 & diverges & $9^{*}$ & 5 \\
\hline
\end{tabular}

* indicates a low voltage solution was obtained

Table 1: Convergence of models from wide-angle starting points for 3-node network

\begin{tabular}{|c|c|c|c|c|c|c|}
\hline Node & $\mathrm{V}(\mathrm{pu})$ & $\mathrm{V}^{\prime}(\mathrm{pu})$ & $\mathrm{V}^{\prime \prime}(\mathrm{pu})$ & $\theta$ (rad.) & $\theta^{\prime}$ (rad.) & $\theta^{\prime \prime}(\mathrm{rad})$. \\
\hline 1 & 1.0 & 1.0 & 1.0 & 0.0 & 0.0 & 0.0 \\
\hline 2 & 0.9140 & 0.9140 & 0.9226 & -0.0987 & -0.0985 & -0.0976 \\
\hline 3 & 0.8725 & 0.8725 & 0.8830 & -0.1551 & -0.1549 & -0.1528 \\
\hline
\end{tabular}

Table 2a: Normal (high voltage) solutions for alternative models for 3-node network

\begin{tabular}{|c|c|c|c|c|}
\hline Node & $\mathrm{V}(\mathrm{pu})$ & $\mathrm{V}^{\prime}(\mathrm{pu})$ & $\theta(\mathrm{rad})$. & $\theta^{\prime}(\mathrm{rad})$. \\
\hline 1 & 1.0 & 1.0 & 0.0 & 0.0 \\
\hline 2 & 0.5107 & 0.5095 & -0.1772 & -0.1767 \\
\hline 3 & 0.1375 & 0.1326 & -0.8728 & -0.8426 \\
\hline
\end{tabular}

Table 2b: Low voltage solutions obtained in some cases for 3-node network

\subsection{Heavily loaded networks}

The tests presented in the previous section are academic, since the network is reasonably easy to solve from a flat start, and the convergence difficulties were created artificially by using wide-angled starting voltages. This section will examine more heavily loaded networks for which practical convergence problems may exist. 
The 3-node test network used in the previous section has been modified by changing the parameters of both lines to $R=0.005 \mathrm{pu}, \mathrm{X}=0.05 \mathrm{pu}, \mathrm{B}=0.2 \mathrm{pu}$ and increasing the load at node 2 to $\mathrm{P}_{2}=-3.0 \mathrm{pu}, \mathrm{Q}_{2}=-0.5 \mathrm{pu}$. The reactive load on node 3 is $\mathrm{Q}_{3}=-0.5 \mathrm{pu}$, but the active power load on node 3 will be varied. Table 3 shows the number of iterations required to converge, for each model, over a range of active power load levels on node 3.

\begin{tabular}{|c|c|c|c|c|}
\hline \multirow{2}{*}{$\begin{array}{l}\text { Active power load } \\
\mathrm{P}_{3} \text { (per unit) }\end{array}$} & \multicolumn{4}{|c|}{ Number of iterations required to converge } \\
\cline { 2 - 5 } & AC & PL-1 & PL-2 & $\begin{array}{c}\text { Sequential } \\
\text { ( PL-2 + PL-1 + AC ) }\end{array}$ \\
\hline 3.0 & 7 & 7 & 4 & $4+5+4$ \\
\hline 3.03125 & 8 & 7 & 4 & $4+6+4$ \\
\hline 3.0625 & diverges & 7 & 4 & $4+6+$ diverges \\
\hline 3.125 & diverges & diverges & 4 & $4+$ diverges + n.a. \\
\hline 7.0 & diverges & diverges & 4 & $4+$ diverges + n.a. \\
\hline 15.0 & diverges & diverges & 6 & $6+$ diverges + n.a. \\
\hline 17.5 & diverges & diverges & 7 & $7+$ diverges + n.a. \\
\hline 20.0 & diverges & diverges & diverges & diverges + n.a. + n.a. \\
\hline
\end{tabular}

Table 3: Convergence of models for heavily-loaded 3-node network

It can be seen that the Newton Raphson process applied to the AC model is able to converge (from a flat start) up to a load level of $\mathrm{P}_{3}=3.03125 \mathrm{pu}$. The PL-1 model is able to converge up to $\mathrm{P}_{3}=3.0625 \mathrm{pu}$, and the PL-2 model can converge up to $\mathrm{P}_{3}=17.5 \mathrm{pu}$. These results illustrate that the pseudo-loadflow models have a wider range of convergence than the AC model, and could therefore be useful as a diagnostic aid for networks which do not seem to have any conventional AC solution.

For a load level $\mathrm{P}_{3}=3.03125 \mathrm{pu}$, the true AC solution $(\mathrm{V}, \theta)$, the PL-1 solution $\left(\mathrm{V}^{\prime}, \theta^{\prime}\right)$ and PL-2 solution $\left(\mathrm{V}^{\prime \prime}, \theta^{\prime \prime}\right)$ are presented in Table 4. Under this heavy load condition (which is the maximum load for which the NR process converges with the $\mathrm{AC}$ model) the pseudo-loadflow solutions are a relatively poor approximation to the AC loadflow, but they can be seen to provide an improved starting point for the AC model. 


\begin{tabular}{|c|c|c|c|c|c|c|}
\hline Node & $\mathrm{V}(\mathrm{pu})$ & $\mathrm{V}^{\prime}(\mathrm{pu})$ & $\mathrm{V}^{\prime \prime}(\mathrm{pu})$ & $\theta$ (rad.) & $\theta^{\prime}(\mathrm{rad})$. & $\theta^{\prime \prime}(\mathrm{rad})$. \\
\hline 1 & 1.0 & 1.0 & 1.0 & 0.0 & 0.0 & 0.0 \\
\hline 2 & 0.7410 & 0.7620 & 0.9250 & -0.4129 & -0.3903 & -0.3220 \\
\hline 3 & 0.6449 & 0.6735 & 0.8840 & -0.7305 & -0.6812 & -0.5047 \\
\hline
\end{tabular}

Table 4: Model solutions for heavily-loaded 3-node network

A further test was undertaken to examine whether a converged $\mathrm{AC}$ model could be obtained at $\mathrm{P}_{3}=3.0625$ pu by solving the PL-2, PL-1 and AC models sequentially, using the converged solution from each model as a starting point for the subsequent (more accurate) model. This approach did not improve on the AC result in this case and led to the sequence of iterations: (PL-2: 4 iterations, PL-1: 6 iterations, AC: diverges). The results of applying the sequential approach at other loading levels are also shown in Table 3. The sequential approach was found to be beneficial in some other cases considered later, but was never found to give any improvement when convergence difficulties were created by heavy loading (over a range of test cases). One possible explanation is that the NR algorithm used incorporates a number of features to encourage convergence (briefly described in Appendix 3) and hence the NR process is able to converge the AC loadflow at load levels close to the maximum feasible load.

\subsection{Networks with high levels of shunt reactance}

Networks with high levels of reactive compensation may also cause convergence problems for the NR solution of the AC loadflow problem. To investigate this aspect, a shunt capacitor was introduced into the modified 3-node test network at node 3, with loads $\mathrm{P}_{2}, \mathrm{P}_{3}=-1.0 \mathrm{pu}$ and $\mathrm{Q}_{2}, \mathrm{Q}_{3}=-0.5 \mathrm{pu}$. Table 5 shows the convergence performance, with various shunt capacitor susceptances, of the NR process for the AC model and for the sequential approach (in which PL-2 is used to provide a starting point for PL-1, which in turn is used to give a starting point for the AC model). In the sequential approach, each model is converged to a mismatch of less than 
$10^{-8} \mathrm{pu}$ and there is no attempt to obtain speed improvements by only partially converging the PL-2 and PL-1 models. The sequential starting process enables convergence of the AC model for shunt values between $4.48 \mathrm{pu}$ and $4.55 \mathrm{pu}$, where convergence could not be obtained by the conventional AC NR process from a flat start. There is an interesting case, for $\mathrm{B}_{3}=4.6 \mathrm{pu}$, where the conventional process finds a low voltage solution, but the sequential process finds the normal high voltage solution. Interestingly, the conventional process is again able to converge successfully over the range $B_{3}=4.7$ pu to $B_{3}=4.995$ pu. It is important to note that in all the cases studied (including many additional cases not presented here) the sequential process always converged whenever the conventional process converged.

\begin{tabular}{|c|c|c|}
\hline \multirow{2}{*}{\begin{tabular}{l} 
Shunt $\begin{array}{l}\text { susceptance } \\
\text { B (per unit) }\end{array}$ \\
\cline { 2 - 3 }
\end{tabular}} & \multicolumn{2}{|c|}{ Number of iterations required to converge } \\
\hline 2.0 & 4 & $\begin{array}{c}\text { Sequential } \\
\text { (PL-2 + PL-1 + AC ) }\end{array}$ \\
\hline 4.4 & 9 & $4+3+2$ \\
\hline 4.45 & 12 & $7+3+2$ \\
\hline 4.47 & 12 & $7+3+2$ \\
\hline 4.48 & diverges & $7+3+2$ \\
\hline 4.49 & diverges & $7+3+2$ \\
\hline 4.5 & diverges & $7+3+2$ \\
\hline 4.51 & diverges & $8+3+2$ \\
\hline 4.52 & diverges & $8+3+2$ \\
\hline 4.55 & diverges & $8+3+2$ \\
\hline 4.6 & $16^{*}$ & $8+3+2$ \\
\hline 4.7 & 8 & $8+3+2$ \\
\hline 4.8 & 9 & $9+3+2$ \\
\hline 4.95 & 9 & $9+3+2$ \\
\hline 4.98 & 10 & $10+3+2$ \\
\hline 4.99 & 10 & $10+3+2$ \\
\hline 4.995 & 10 & $10+3+2$ \\
\hline 5.0 & diverges & diverges + n.a. + n.a. \\
\hline 5.2 & diverges & diverges + n.a. + n.a. \\
\hline 5.5 & diverges & diverges + n.a. + n.a. \\
\hline
\end{tabular}

* indicates a low voltage solution was obtained

Table 5: Convergence of models for modified 3-node test network 
To study the effect of high levels of shunt reactance further, the IEEE 30 node test network [12], which includes two shunt capacitors, has been modified by artificially increasing the susceptance of these shunts by a factor $\lambda$.

Table 6 shows the convergence performance of the NR process for the AC model and for the sequential approach.

This test problem includes effective Q-limits at generators, and the stabilised approach to node type switching (described in Appendix 3) results in 7 iterations being required for NR convergence of the AC model with the normal shunt parameters $(\lambda=1.0)$. The sequential starting process does not help to achieve AC convergence for shunt multiples up to $\lambda=180$, nor $\lambda=205.0$ and above. However, there is a range from $\lambda=185.0$ to $\lambda=200.0$ over which the sequential starting process allows an AC solution to be found, where none could be found using the conventional AC loadflow from a flat start.

\begin{tabular}{|c|c|c|}
\hline \multirow{2}{*}{$\begin{array}{c}\text { Multiplier for nodal } \\
\text { shunt susceptances } \lambda\end{array}$} & \multicolumn{2}{|l|}{ Number of iterations required to converge } \\
\cline { 2 - 3 } & & $\begin{array}{c}\text { Sequential } \\
\text { ( PL-2 + PL-1 + AC ) }\end{array}$ \\
\hline 1.0 & 7 & $5+4+2$ \\
\hline 100.0 & 10 & $5+3+7$ \\
\hline 150.0 & 22 & $6+3+18$ \\
\hline 155.0 & diverges & $7+3+$ diverges \\
\hline 160.0 & diverges & $7+3+$ diverges \\
\hline 175.0 & diverges & $7+3+$ diverges \\
\hline 180.0 & diverges & $8+3+$ diverges \\
\hline 185.0 & diverges & $8+3+13$ \\
\hline 190.0 & diverges & $8+3+12$ \\
\hline 200.0 & diverges & $9+3+11$ \\
\hline 205.0 & diverges & $9+3+$ diverges \\
\hline 210.0 & diverges & $10+3+$ diverges \\
\hline 220.0 & diverges & diverges + n.a. + n.a. \\
\hline
\end{tabular}

Table 6: Convergence of models for modified IEEE 30 node test network 


\subsection{Large scale networks}

Larger scale test problems [11,12] have also been solved to confirm the performance of the proposed models on practical sized networks. Table 7 presents the convergence performance of the models for larger networks. These models do not include node type switching, and hence the NR AC model is able to converge to within $10^{-8} \mathrm{pu}$ in 4 iterations. The sequential process is able to converge as expected for these larger systems, confirming the quadratic convergence of the NR process applied to the pseudo-loadflow models. No new qualitative phenomena were observed in a range of tests on these larger networks. The computer time (using a 3.4GHz Pentium IV) needed to solve these networks could not be measured exactly, but was a small fraction of a second in each case.

\begin{tabular}{|c|c|c|}
\hline $\begin{array}{l}\text { Number of network } \\
\text { nodes }\end{array}$ & \multicolumn{2}{|c|}{ Number of iterations required to converge } \\
\cline { 2 - 3 } & AC & $\begin{array}{c}\text { Sequential } \\
\text { ( PL-2 + PL-1 + AC ) }\end{array}$ \\
\hline 118 & 4 & $3+3+2$ \\
\hline 629 & 4 & $3+3+2$ \\
\hline 734 & 4 & $3+3+2$ \\
\hline
\end{tabular}

Table 7: $\underline{\text { Convergence of models for larger test networks }}$

\section{CONCLUSIONS}

New approximate loadflow models have been presented which are intermediate between the AC and DC loadflow models. These pseudo-loadflows have been demonstrated to provide a useful starting process for the solution of AC loadflow models which exhibit convergence difficulties. In particular networks with high levels of reactive compensation can be successfully solved where the conventional method diverges. Since the pseudo-loadflow models have a wider range of convergence (for the Newton-Raphson process) than the conventional AC model, they may also be useful to diagnose physical, or data-related, problems in difficult networks. By applying the 
Newton Raphson process to the pseudo-loadflow models, quadratic convergence can be obtained giving good computational efficiency.

\section{REFERENCES}

[1] W.F. Tinney and C.E. Hart, "Power Flow Solution by Newton's Method", IEEE Trans. Power App. Syst., Vol. PAS-86, pp1449-1456, November 1967

[2] B. Stott, "Review of Load-Flow Calculation Methods", Proc. IEEE, Vol. 62, No. 7, pp 916-929, July 1974

[3] L.M.C. Braz, C.A. Castro and C.A.F. Murari, "A Critical Evaluation of Step Size Optimization Based Load Flow Methods", IEEE Transactions on Power Systems, Vol. 15, No. 1, pp 202-207, February 2000

[4] S.C. Lee and K.B. Park, "Flexible Alternatives to Decoupled Load Flows at Minimal Computational Costs" Int. Jnl. of Electrical Power and Energy Systems, Vol. 25, pp 319-326, 2003

[5] P.R. Bijwe and S.M. Kelapure, "Nondivergent Fast Power Flow Methods", IEEE Transactions on Power Systems, Vol. 18, No. 2, pp 633-638, May 2003

[6] J.E. Tate and T.J. Overbye, "A Comparison of the Optimal Multiplier in Polar and Rectangular Coordinates", IEEE Transactions on Power Systems, Vol. 20, No. 4, pp 1667-1674, November 2005

[7] F. Milano, "Continuous Newton's Method for Power Flow Analysis", IEEE Transactions on Power Systems, Vol. 24, No. 1, pp 50-57, February 2009

[8] T.J. Overbye, “A Power Flow Measure for Unsolvable Cases”, IEEE Transactions on Power Systems, Vol. 9, No. 3, pp 1359-1365, August 1994

[9] B. Stott, "Effective starting process for Newton-Raphson Load Flows", Proc. IEE, Vol. 118, No. 8, pp 983-987, August 1971

[10] B. Stott and O. Alsac, "Fast Decoupled Load Flow", IEEE Trans. Power App. Syst., Vol. PAS-93, pp 859-869, June 1974 
[11] M.R. Irving and M.J.H. Sterling, "Efficient Newton-Raphson Algorithm for Load-Flow Calculation in Transmission and Distribution Networks”, Proc. IEE Part (C), Vol. 134, No. 5, pp 325-328, September 1987

[12] University of Washington Electrical Engineering, Power System Test Case Archive, May 2009, http://www.ee.washington.edu/research/pstca/

[13] E. Acha, C.R. Fuerte-Esquivel, H. Ambriz-Perez, C. Angeles-Camacho, "FACTS - Modelling and Simulation in Power Networks", John Wiley and Sons, Chichester, 2004

[14] A. Vinkovic and R. Mihalic, "A current-based model of the static synchronous series compensator (SSSC) for Newton-Raphson power flow”, Electric Power Systems Research, Vol. 78, pp1806-1813, 2008

[15] A. Vinkovic and R. Mihalic, "A current-based model of an IPFC for Newton-Raphson power flow", Electric Power Systems Research, Vol. 79, pp1247-1254, 2009

[16] A. Karami and M.S. Mohammadi, "Radial basis function neural network for power system load-flow", Int. Jnl. of Electrical Power and Energy Systems, Vol. 30, pp 60-66, 2008

[17] J. Usaola, "Probabilistic load flow with wind production uncertainty using cumulants and Cornish-Fisher expansion”, Int. Jnl. of Electrical Power and Energy Systems, Vol. 31, pp 474-481, 2009

\section{APPENDIX 1}

The Jacobian elements for the pseudo-loadflow type-1 (PL-1) equations, (3) and (4), are:

$$
\begin{array}{ll}
\delta P_{i} / \delta \theta_{i}^{\prime}= & -V_{i}^{\prime} \sum_{(j=1, n)} V_{j}^{\prime}\left(G_{i j}\left(\theta_{i}^{\prime}-\theta_{j}^{\prime}\right)-B_{i j}\right) \\
\delta P_{i} / \delta \theta_{j}^{\prime}= & V_{i}^{\prime} V_{j}^{\prime}\left(G_{i j}\left(\theta_{i}^{\prime}-\theta_{j}^{\prime}\right)-B_{i j}\right) \\
\delta P_{i} / \delta V_{i}^{\prime}= & V_{i}^{\prime} G_{i i}+P_{i} / V_{i}^{\prime} \\
\delta P_{i} / \delta V_{j}^{\prime}= & V_{i}^{\prime}\left(G_{i j}\left(1-\left(\theta_{i}^{\prime}-\theta_{j}^{\prime}\right)^{2} / 2\right)+B_{i j}\left(\theta_{i}^{\prime}-\theta_{j}^{\prime}\right)\right)
\end{array}
$$




$$
\begin{array}{ll}
\delta \mathrm{Q}_{\mathrm{i}} / \delta \theta_{\mathrm{i}}^{\prime}= & \mathrm{V}_{\mathrm{i}}^{\prime} \sum_{(\mathrm{j}=1, \mathrm{n})} \mathrm{V}_{\mathrm{j}}^{\prime}\left(\mathrm{G}_{\mathrm{ij}}+\mathrm{B}_{\mathrm{ij}}\left(\theta_{\mathrm{i}}^{\prime}-\theta_{\mathrm{j}}^{\prime}\right)\right) \\
\delta \mathrm{Q}_{\mathrm{i}} / \delta \theta_{\mathrm{j}}^{\prime}= & -\mathrm{V}_{\mathrm{i}}^{\prime} \mathrm{V}_{\mathrm{j}}^{\prime}\left(\mathrm{G}_{\mathrm{ij}}+\mathrm{B}_{\mathrm{ij}}\left(\theta_{\mathrm{i}}^{\prime}-\theta_{\mathrm{j}}^{\prime}\right)\right) \\
\delta \mathrm{Q}_{\mathrm{i}} / \delta \mathrm{V}_{\mathrm{i}}^{\prime}= & -\mathrm{V}_{\mathrm{i}}^{\prime} \mathrm{B}_{\mathrm{ii}}+\mathrm{Q}_{\mathrm{i}} / \mathrm{V}_{\mathrm{i}}^{\prime} \\
\delta \mathrm{Q}_{\mathrm{i}} / \delta \mathrm{V}_{\mathrm{j}}^{\prime}= & \mathrm{V}_{\mathrm{i}}^{\prime}\left(\mathrm{G}_{\mathrm{ij}}\left(\theta_{\mathrm{i}}^{\prime}-\theta_{\mathrm{j}}^{\prime}\right)-\mathrm{B}_{\mathrm{ij}}\left(1-\left(\theta_{\mathrm{i}}^{\prime}-\theta_{\mathrm{j}}^{\prime}\right)^{2} / 2\right)\right)
\end{array}
$$

The Jacobian elements for the pseudo-loadflow type-2 (PL-2) equations, (5) and (6), are:

$$
\begin{aligned}
& \delta P_{i} / \delta \theta^{\prime \prime}{ }_{i}=V^{\prime \prime} \sum_{(j=1, n)} V^{\prime \prime} B_{i j} \\
& \delta P_{i} / \delta \theta^{\prime \prime}{ }_{j}=-V^{\prime \prime}{ }_{i} V_{j} B_{i j} \\
& \delta P_{i} / \delta V^{\prime \prime}=V_{i}^{\prime \prime} G_{i i}+P_{i} / V^{\prime \prime} \\
& \delta P_{i} / \delta V^{\prime \prime}{ }_{j}=V_{i}^{\prime \prime}\left(G_{i j}+B_{i j}\left(\theta_{i}^{\prime \prime}-\theta_{j}{ }_{j}\right)\right) \\
& \delta Q_{i} / \delta \theta^{\prime \prime}{ }_{i}=\quad V^{\prime \prime} \sum_{(j=1, n)} V^{\prime \prime} G_{i j} \\
& \delta Q_{i} / \delta \theta^{\prime \prime}{ }_{j}=-V^{\prime \prime}{ }_{i}{ }^{\prime \prime}{ }_{j} G_{i j} \\
& \delta Q_{i} / \delta V^{\prime \prime}{ }_{i}=-V^{\prime \prime}{ }_{i} B_{i i}+Q_{i} / V^{\prime \prime}{ }_{i} \\
& \delta Q_{i} / \delta V^{\prime \prime}=V^{\prime \prime}\left(G_{i j}\left(\theta_{i}^{\prime \prime}-\theta_{j}{ }_{j}\right)-B_{i j}\right)
\end{aligned}
$$

\section{APPENDIX 2}

The three node test network used in section 3.1 has the following data:

\begin{tabular}{|c|c|c|c|c|}
\hline Node & $\begin{array}{c}\text { Net Active } \\
\text { Power Injection } \\
\text { P (per unit) }\end{array}$ & $\begin{array}{c}\text { Net Reactive } \\
\text { Power Injection } \\
\text { Q (per unit) }\end{array}$ & $\begin{array}{c}\text { Nodal Shunt } \\
\text { Susceptance } \\
\text { B (per unit) }\end{array}$ & $\begin{array}{c}\text { Nodal Shunt } \\
\text { Conductance } \\
\text { G (per unit) }\end{array}$ \\
\hline 1 & (slack) & (slack) & 0.0 & 0.0 \\
\hline 2 & -1.0 & -0.5 & 0.0 & 0.0 \\
\hline 3 & -1.0 & -0.5 & 0.0 & 0.0 \\
\hline
\end{tabular}

Table A2.1: Node data for 3-node Test Network 


\begin{tabular}{|c|c|c|c|c|}
\hline Sending Node & Receiving Node & $\begin{array}{l}\text { Branch Resistance } \\
\text { R (per unit) }\end{array}$ & $\begin{array}{l}\text { Branch Reactance } \\
\text { X (per unit) }\end{array}$ & $\begin{array}{l}\text { Total Charging } \\
\text { Susceptance B (per unit) }\end{array}$ \\
\hline 1 & 2 & 0.01 & 0.05 & 0.002 \\
\hline 2 & 3 & 0.01 & 0.05 & 0.002 \\
\hline
\end{tabular}

Table A2.2: Branch data for 3-node Test Network

\section{APPENDIX 3}

The Newton Raphson algorithm which has been used has a number of features which are designed to enhance convergence. These are briefly described in the following subsections.

\section{A3.1 Limits on Voltage Magnitude and Angle Increments}

The voltage magnitude increments determined by the NR process are limited to \pm 0.25 per unit, and the voltage phase angle increments are limited to $\pm \pi / 4$ radians. This tends to reduce the possibility for divergence, especially during the initial iterations.

\section{A3.2 Numerical Precision}

All numerical calculations are performed with 64-bit precision. The use of high precision avoids ill-conditioning that can arise from Jacobian matrices with widely varying coefficient values (e.g. due to a combination of very high and very low per unit impedances in the same network).

\section{A3.3 Node Type Switching}

Switching of PV-type nodes to PQ-type nodes (when Q limits are exceeded) can destabilize the convergence of the 
NR process if switching decisions are based on non-converged information. In the present implementation, node type switching is only performed in iterations where the maximum mismatch is less than $5.0 \times 10^{-2}$ per unit.

\section{A3.4 Sub-matrix Processing}

The solution of the Jacobian equation, via sparse matrix methods, in loadflow algorithms, usually relies on diagonal pivoting for sparsity preservation. By applying a technique [11], in which each sparse matrix element is itself a $2 \times 2$ sub-matrix, it is possible to preserve numerical stability in cases where either the $\delta \mathrm{P} / \delta \theta$ coefficient or the $\delta \mathrm{Q} / \delta \mathrm{V}$ coefficient (but not both) become too small in magnitude for good numerical stability.

(This can arise for networks with significant reactive compensation, e.g. series capacitors.) 